\title{
Социализация и самореализация как ключевые мотивы медиапотребления
}

\author{
(опыт исследования поколения Z в России)
}

Денис Дунас

В фокусе исследовательского внимания автора статьи медиапотребление "цифрового» поколения россиян, или поколения Z (возрастная группа 10-19 лет).

Сбор эмпирических данных производился методами глубинных интервью и опроса представителей трех российских городов: Москвы, Нижнего Новгорода и Ростова-на-Дону. Результаты исследования выявили, что молодые россияне в процессе использования медиа стремятся удовлетворить потребности, связанные в первую очередь с социальной природой человека, а именно: потребность в социализации и самореализации.

Ключевые слова: медиапотребление, поколение Z, социализация, самореализация, молодежь.

DOI: 10.30547/mediaalmanah.5.2020.2534
@ Дунас Денис Владимирович

кандидат филологических наук, доцент РАО,

ведущий научный сотрудник

кафедры теории и экономики СМИ

факультета журналистики

МГУ имени М.В. Ломоносова

(г. Москва, Россия), dunas.denis@smi.msu.ru

\section{Введение}

Современные информационно-коммуникационные технологии способствуют появлению качественно новых явлений в повседневной жизни молодых россиян. Цифровые медиа, с одной стороны, таят в себе множество новых социокультурных угроз, становятся источником идеологического экстремизма, киберугроз, политической радикализации, девиантного поведения, мобилизации вокруг деструктивных лидеров мнений, агентов влияния, в том числе иностранных; с другой стороны, онлайн-медиапрактики открывают пользователям возможности многосторонней сетевой коммуникации, социализации, образования и самореализации, гражданской активности, борьбы за идеалы социальной справедливости и социального прогресса, возможности для личностного развития, способствуют повышению качества жизни, диверсификации стиля жизни и культурных практик, разнообразию досуга (Castells, 2001).

Очевидно, что современные медиакоммуникации представляют собой и прорывные, и «подрывные технологии/инновации» (disruptive technologies/innovations) - то есть такие, которые, способствуя революционному скачку в общественном и индивидуальном развитии, вместе с тем формируют и определенные угрозы существующим 
институциональным государственным моделям, общественным нормам, традиционным культурным ценностям (Вартанова, 2015; Ткачева, Вартанов, Дунас, Гуреева, 2016).

Научную проблему представляет отсутствие в современном академическом знании понимания мотивационных факторов потребления медиа молодыми россиянами - теми, кого все чаще называют «цифровой молодежью» (Вартанова, 2017; Солдатова, Рассказова, 2017). Сегодня это наименее изученная часть медиааудитории, поскольку не все ее представители достигли совершеннолетнего возраста и попали в полном объеме в выборку медиаизмерителей. Отметим, однако, что именно эта часть аудитории в дальнейшем станет активной силой отечественной общественной и политической жизни. Кроме того, имеющиеся данные о структуре и объемах медиапотребления не дают ответа на вопрос о причинах выбора того или иного медиаконтента - целях и потребностях, факторах мотивации молодых россиян при выборе контента, медиаплатформ и социальных сетей.

Очевиден недостаток в исследованиях медиапотребления различных возрастных групп «цифровой молодежи», которые не только носили бы постановочно концептуальный характер, но и основывались на актуальных эмпирических данных и учитывали российский опыт взаимоотношений медиа и молодежи.

Особую значимость решение этой научной проблемы приобретает в контексте обеспечения информационной безопасности российского общества и молодежи в цифровой среде.

Концептуальная рамка исследования

Теория использования (медиа) и (получения) удовлетворения (uses and gratification theory) была выработана в рамках доминирующей парадигмы медиаисследований - эмпирико-функционализма и представляет собой теорию среднего уровня, объясняющую причины, или другими словами, мотивации или потребности, которые движут аудиторией при использовании медиа (Katz, Blumler, Gurevitch, 1973; Kurzban, Burton-Chellew, West, 2015; Lang, Bradley, 2010; Lee, Ma, 2012; Palmgreen, Wenner, Rayburn, 1980; Sundar, Limperos, 2013; Quan-Haase, Young, 2010). На русский язык понятие gratification также может быть переведено как «удовольствие» или «вознаграждение», однако академически наиболее корректным вариантом перевода в данном контексте представляется именно «удовлетворение».

В попытке систематизировать мотивации, которые играют ключевую роль для аудитории в решении потреблять определенное средство массовой информации или контент, были определены 35 потребностей, сгруппированных по пяти категориям (Katz, Blumler, Gurevitch, 1973). Они включают:

- познавательные потребности, или потребности в знаниях, а также в информации;

- аффективные потребности (эстетический и эмоциональный опыт);

- сочетание познавательных и аффективных потребностей, таких как укрепление уверенности в себе, поддержание статуса;

- потребности социальной интеграции, необходимые для усиления связи с семьей, друзьями и миром;

- необходимость эскапизма или снятия напряжения (Katz, Blumler, Gurevitch, 1973: 521-523).

Традиционное понимание теории использования и удовлетворения предполагает, что аудитория реализует свои потребности не напрямую, а опосредованно, в результате акта медиации:

- физиологические потребности удовлетворяются через получение из медиа информации о товарах первой необходимости;

- потребности в безопасности и защите от внешней среды удовлетворяются путем 
получения информации о происходящем в мире;

- социальные потребности удовлетворяются, когда полученная из медиа информация становится поводом для общения либо для собственного выступления в медиа;

- потребности в оценке и признании реализуются через потребление «статусных» медиа и демонстрацию своей принадлежности к престижной социальной группе;

- потребности в самореализации удовлетворяются тогда, когда человек использует опубликованную в медиа информацию для своей творческой работы (Финк, 2004: 134-135).

Классификация Д. МакКуэйла (2002) объединяет потребности, удовлетворяемые опосредованно, с потребностями, которые реализуются напрямую:

- информационные потребности - ориентирование в окружающей действительности, поиск совета, забота о безопасности через информирование о возможных угрозах, любопытство и тяга к знанию;

- потребности в самоидентификации подкрепление своих взглядов, поиск моделей поведения, сопоставление себя с другими, самоанализ;

- потребности в интеграции и социальном взаимодействии - воображаемое помещение себя в жизненные обстоятельства других, ощущение принадлежности к какой-либо общности, поиск контактов, помощь в выборе социальных ролей и материал для разговора с другими людьми, замена реального общения;

- потребности в развлечении - уход от действительности, заполнение времени, получение культурного и эстетического удовольствия, эмоциональная разрядка, снятие напряжения и сексуальная стимуляция (McQuail, 2002: 27-28).

Однако сегодня медиация (Berger, Luckmann, 1966) уступила первенство представлениям о медиатизации (Couldry, Hepp, 2016) и, соответственно, способности медиа не столько опосредованно, сколько имманентно влиять на аудиторию. Было установлено, что аудитория использует СМИ для удовлетворения самых разных потребностей, а не только информационных. Типология медиапотребностей коррелирует с тем, что аудитория получает от взаимодействия с реальными людьми (Palmgreen, Wenner, Rayburn, 1980: 165). Обращаясь к рассмотрению потребностей человека по Маслоу, мы обнаруживаем, что в результате медиапотребления могут быть в той или иной степени реализованы большинство мотивов человека (кроме некоторых физиологических):

- физиологические: голод, жажда, половое влечение и т.д.;

- экзистенциальные: безопасность существования, комфорт, постоянство условий жизни;

- социальные: общение, взаимодействие, привязанность, забота о другом и внимание к себе, совместная деятельность;

- престижные: самоуважение, уважение со стороны других, признание, достижение успеха и высокой оценки, служебный рост;

- духовные: познание, самореализация, самовыражение, самоидентификация (Maslow, 1970).

Исследования потребностей аудитории социальных медиа возможно классифицировать следующим образом:

- времяпровождение (чтобы убить время / потому что это интересно / потому что это нравится / потому что это весело / потому что это приятный отдых / потому что это расслабляет / чтобы уйти от давления и ответственности / чтобы уйти оттого, что я делаю / отложить на потом что-то, что нужно сделать);

- привязанность к сообществу (чтобы поблагодарить людей / чтобы люди знали, что о них заботятся / демонстрировать другие поощрения / чтобы помогать другим / показывать другим, что о них беспокоятся);

- мода и самореализация (чтобы не выглядеть старомодным / чтобы выглядеть 
стильно / чтобы выглядеть модно / делиться актуальными проблемами / потому что нужен кто-то, с кем можно поговорить или с кем быть / потому что просто нужно иногда говорить о проблемах / забыть о проблемах);

- общение (чтобы подружиться с людьми / чтобы быть менее подавленным в чате с незнакомыми людьми / чтобы познакомиться с новыми людьми);

- получение социальной информации (чтобы понять, что происходит с другими людьми) (Quan-Haase, Young, 2010).

Аудитория не отделяет потребности от использования медиа от своих потребностей в целом, что подтверждает концепция самодетерминации Э Деси и Р. Райана (2008). Согласно концепции самодетерминации в основе внутренней мотивации личности заложены три базовые мотивации - компетентность, автономия и связанность с другими людьми. Именно эти три потребности сегодня реализуются в акте медиапотребления, прежде всего в цифровой среде, наилучшим образом. Ряд исследований, в первую очередь зарубежных, убедительно доказывают, что использование подростками социальных сетей снижает чувство одиночества, формирует чувство общности и более высокий уровень социальной компетентности и обеспечивает в целом психологическое благополучие личности (Солдатова, Рассказова, Нестик, 2017: 45).

\section{Методы исследования: глубинные интервью и опрос}

В рамках проекта РНФ № 18-78-10090 «Медиапотребление "цифровой молодежи" в России: современные особенности и факторы мотивации» были проанализированы глубинные интервью, проведенные с представителями «цифрового поколения" россиян в трех городах: Москве, Нижнем Новгороде и Ростове-на-Дону (по восемь интервью в каждом городе). Пилотное исследование позволило предусмотреть возможные закрытые вопросы и варианты ответов на них и впоследствии включить их в анкету массового репрезентативного опроса. Кроме того, глубинные интервью были призваны сопоставить существующие научные гипотезы с результатами изучения медиапотребления «цифровой молодежи». В выборку исследования были включены школьники средних классов - возрастная группа 10-15 лет (родились с 2003 по 2008 г.); школьники старших классов - 16-17 лет (родились с 2002 по 2003 г.); студенты вузов - 17-19 лет (родились с 1999 по 2001 г.). Формирование выборочной совокупности осуществлялось методом реализации процедуры случайно-вероятностного отбора с соблюдением гендерного баланса. Для интервью был разработан сценарий (топик-гайд), состоящий из 12 блоков: приоритеты платформы; телесмотрение; обращение к радио; востребованность подкастов; потребление новостей в Интернете; тип контента, потребляемого в Интернете; чтение печатной прессы; востребованность мобильных приложений; тип контента, потребляемого с мобильных устройств; востребованность соцсетей, мотивы обращения к ним; востребованность мессенджеров, мотивы обращения к ним; востребованность различных медиаплатформ.

Каждое интервью представляло собой индивидуальную беседу с респондентом продолжительностью 1-1,5 ч. Глубинные интервью предполагали получение от респондента развернутых ответов на вопросы, а не простое заполнение формальной анкеты. У интервьюеров был общий план ведения беседы, хотя на деле порядок вопросов и их формулировки могли существенно меняться, в зависимости оттого, как отвечал респондент. Каждая запись была расшифрована, в результате чего исследовательский коллектив мог проанализировать тексты всех интервью. Глубинные интервью способствовали достижению понимания специфики медиапотребления представителей целевой аудитории, 
а также обнаружению непредвиденных проблемных зон в теоретическом исследовании цифрового медиапотребления и его мотиваций. После получения транскриптов всех интервью была проведена систематизация ответов респондентов, представляющая собой цитатники, заполненные отрывками из интервью, состоящие из четырех блоков: предпочитаемые формы медиапотребления (платформа/канал/устройство); выявление приоритетов по контенту; востребованность различных медиаресурсов; удовлетворение потребностей.

В рамках проекта были проведены не только глубинные интервью, но и опрос. Генеральную совокупность для каждого из городов составили представители поколения $Z$, или совокупность детей и молодежи от 10 до 19 лет, обучающихся в средних образовательных учреждениях и вузах (от пятого класса школы до второго курса вуза). На основании этих условий был сформирован дизайн выборки с общей выборочной совокупностью 4320 анкет, из которых в каждом городе предполагалось получить по 960 анкет школьников (10-17 лет) и по 480 анкет студентов вузов (17-19 лет), что соответствует 2880 и 1440 анкетам по обеим целевым аудиториям в городах. Формирование выборочной совокупности осуществлялось в несколько этапов.

На первом этапе была сформирована общая база данных по городам с перечнем общеобразовательных школ и вузов. Списки образовательных организаций были взяты из официальных источников: с сайта департамента образования Москвы, с сайта министерства общего и профессионального образования Ростовской области, с сайта министерства образования, науки и молодежной политики Нижегородской области. В базу данных по городам включались все средние общеобразовательные учреждения (за исключением специализированных коррекционных школ) и образовательные организации высшего профессионального образования. В результате проделанной работы в базу данных вошли 650 средних общеобразовательных учреждений и 136 вузов Москвы, 200 средних общеобразовательных учреждений и 30 вузов Нижнего Новгорода, 125 средних общеобразовательных учреждений и 48 вузов Ростова-на-Дону.

На втором этапе была сформирована выборочная совокупность процедурой случайно-вероятностного отбора. В соответствии с расчетными данными, в каждом из городов в выборке присутствовали восемь школ. В каждой школе опрос проводился в семи классах (5-11 классы). Расчетное число получения анкет с каждого класса - 18. В соответствии с расчетными данными, в каждом из городов в выборке присутствовали восемь вузов. Опрос проводился среди студентов первого и второго курсов. Расчетное число анкет с каждого вуза - 60. Из общего списка в каждом из городов случайно-вероятностным методом (генерация случайного отбора в пакете SPSS) были отобраны девять школ и восемь вузов. В результате распределения выборочной совокупности по средним общеобразовательным учреждениям на один город количество анкет с каждого класса школы должно было составить 18, с одного курса вуза - 30.

На третьем этапе на основе контактных данных из открытых информационных источников была сформирована полная база выборочной совокупности. Подготовка к проведению опроса в учебных заведениях включала рассылку информационных писем руководителям образовательных учреждений, содержащих краткое описание тематики исследования и просьбу о содействии в осуществлении этого проекта в данном учебном заведении; получение договоренности о проведении опроса с руководителями образовательных учреждений; согласование сроков и времени проведения опроса с руководителями образовательных учреждений. Большое внимание было уделено подготовке 
анкеты, необходимой для исследования. Как было отмечено, составление анкеты потребовало проведения серии глубинных интервью. Ответы интервьюируемых в дальнейшем использовались при формировании содержательного наполнения основных блоков анкеты. Так, в варианты ответов прежде всего были включены наиболее частые среди тех, что давали интервьюируемые. Кроме того, общение со школьниками позволило использовать при формировании ответов в анкете лексику, характерную и понятную для респондентов определенного возраста, что являлось особенно важным при составлении анкеты для младших участников опроса. В результате было сформировано две анкеты: одна для младшей возрастной группы (детей в возрасте от 10 до 15 лет), вторая для более взрослых респондентов (учеников 10-11 классов и студентов 1-2 курса, то есть респондентов от 16 до 19 лет). Расчетный уровень точности составил $\pm 5 \%$.

В процессе опроса большинство респондентов ответственно отнеслись к заполнению анкеты. Критерием этой ответственности служит полнота заполнения анкеты - в 97\% на все открытые вопросы были даны ответы. Полностью было отбраковано только восемь анкет (заполнение менее 50\%). Процедура ответа на вопросы занимала у респондентов в среднем 40 мин. Перевод полученных результатов опроса с бумажных носителей в электронный виддля последующей обработки осуществлялся в макете ввода формата Exel. Открытые вопросы были кодированы. Для каждого из открытых вопросов был создан кодификатор, и все ответы респондентов были переведены в цифровые показатели. В общей сложности было создано 246 кодов. Далее был создан макет ввода в пакете SPSS для обработки общего массива данных. Таким образом были получены линейные распределения ответов каждого вопроса. Обработка данных была произведена в пакете SPSS.

\section{Результаты проведенного исследования}

Как показали результаты глубинных интервью, новые медиа занимают лидирующую позицию в структуре медиапотребления подростков и молодежи, а традиционные медиа либо вовсе не вызывают их интерес, либо используются по случаю или в фоновом режиме. Ключевым устройством доступа для удовлетворения мотивов является смартфон, доминирующим типом медиа - социальные сети. Как показало исследование, молодежь обращается к медиа для реализации разного типа мотивов: потребность в социализации (прежде всего за счет коммуникации в социальных сетях и информирования о событиях в жизни членов сообщества); потребность в самореализации (прежде всего за счет производства единиц собственного контента и его распространения в социальных сетях); развлекательные потребности (прежде всего за счет прослушивания музыки и потребления видео в Интернете); потребность в получении новостной информации (прежде всего посредством получения социальной информации о событиях, интересных представителям сообщества, которыми они делятся с другими); образовательные потребности (прежде всего за счет поиска информации для выполнения заданий в Интернете); инструментальные потребности (прежде всего мобильный банк и покупки).

Каждый из исследованных мотивов удовлетворяется не только медиапотреблением определенного типа контента, но и конкретными действиями с контентом. Например, потребность в социализации реализуется комплексно: за счет информирования пользователя социальной сети о событиях в жизни окружения, интересного ему (как реальных, так и виртуальных людей); за счет одобрения и распространения производимого ими контента; за счет межличностной коммуникации; за счет получения одобрения производимого пользователем 
контента. В результате реализуется процесс медиасоциализации как гибридная форма социализации современного человека, при котором агентами социализации выступают: 1) существующие в физическом пространстве близкие индивиду «значимые другие», социализация с которыми продолжается в медиапространстве; 2) существующие для индивида только в медиапространстве «значимые другие».

Медиасоциализация, с одной стороны, представляет собой опосредование социальных норм и ценностей реального мира, но с другой - создание норм и ценностей, имманентная сущность которых потенциально возможна только в условиях медиапространства. Активные действия с контентом (создание и распространение, одобрение членами сообщества) способствуют не только социализации в медиапространстве, но и самореализации пользователя. Успешная медиасоциализация есть залог осуществления начальных этапов медиасамоактуализации как процесса реализации различных сторон личности в медиапространстве, приносящих удовлетворение от жизни.

Опрос во многом подтвердил результаты, полученные в ходе глубинных интервью. Наиболее популярными медиа среди подростков и молодежи стали социальные сети «ВКонтакте» (30,7\%), YouTube (25,5\%), Instagram (24\%). Ведущими мотивационными факторами обращения к социальным сетям - потребность в общении с друзьями (около 37\%), прослушивании музыки (свыше $12 \%)$, а также в поиске информации по интересам либо связанной с саморазвитием (почти 12\%). В основном осуществляется поиск нужной в данный момент информации (для учебы, работы, по интересам). То же относится и к мотивации общения: социальная сеть «ВКонтакте» представляется наиболее комфортной для общения с одноклассниками и однокурсниками, для коммуникации с друзьями как в формате обычных сообщений, так и в тематических беседах и пабликах. Упомянутые соцсети также служат источником отдыха и развлечений для респондентов (85\% по трем сетям). К тройке лидеров примыкает TikTok быстро развивающаяся социальная сеть, популярная среди молодежи (10\%). Что касается знакомства с новыми людьми, размещения персональной информации (в том числе личных фото-, видео- и текстовых материалов), наиболее востребованными платформами для школьников и студентов выступают социальные сети «ВКонтакте» и Instagram. Это коррелирует с результатами глубинных интервью и теоретических разработок.

Социальная сеть YouTube стала лидером в области поиска новой информации, связанной с личными интересами респондентов: свыше 41\% отметили, что осуществляют поиск нужной информации через YouTube. Эти данные представляют большой интерес, т.к. в глубинных интервью подобные результаты не были выявлены. Видеоконтент оказался для респондентов наиболее предпочтительным (34,5\%), что позволяет сделать вывод о востребованности YouTube как платформы для поиска и восприятия информации. Среди наиболее востребованных мессенджеров респонденты отметили WhatsApp (свыше 28\%), мессенджеры социальных сетей «ВКонтакте» и Instagram (по 20,4\%), а также мессенджер Telegram, который используют свыше 18\% респондентов. Ключевой особенностью поведения в Интернете среди молодежи является поиск информации по интересам или по требованию (20,6\%), а также потребление аудиовизуального контента (18,2\%). Таким образом, Интернет выступает для молодежи одновременно источником информации о том, что интересно лично ему, и о том, что происходит в стране, мире и т.д., средством развлечения и приятного/полезного времяпрепровождения.

Следует отметить, что студенты вузов минимально потребляют онлайн-игры, контент блогеров, а также реализуют 
инструментальные потребности, выраженные в необходимости приобрести какой-либо товар или услугу, что вполне объяснимо, т.к. у студентов много времени уходит на учебу. В социальные сети и мессенджеры респонденты выходят в основном через свой мобильный телефон - смартфон, который для большинства опрошенных выступает как техническое устройство, с помощью которого они поддерживают связь с друзьями, университетским кругом, родителями, ищут нужную информацию. Было выявлено, что $80 \%$ респондентов не читают печатных версий газет и журналов, почти $65 \%$ опрошенных вообще не смотрят телевидение, а свыше 75\% не слушают радио (24\% респондентов слушают радио, пока едут в машине с родителями).

В структуре мотиваций медиапотребления ключевые позиции занимают потребности, детерминированные социальной природой человека, - социализация и самореализация. Далее следуют развлекательные, информационные, образовательные и инструментальные мотивы (White, Cornu, 2011). Отметим, что каждая отдельная группа мотивов не всегда «замкнута», так как стремится к сближению с другими группами. При этом медиапотребности не связаны исключительно с информационными запросами аудитории. Сегодня медиа уже не только транслируют институциональные нормы и ценности, но формируют и воспроизводят внеинституциональные нормы и ценности посредством «лидеров мнений» и агентов влияния, интегрированных в инфраструктуру цифровых медиа. В результате особенно актуализируется проблема цифровой медиаграмотности и информационной безопасности «цифрового поколения», для которого вопросы критического анализа цифровой медиасреды, знаний о природе медиа будут определять траекторию его социализации.

Большой интерес представляют ответы на заключительные вопросы анкеты о наиболее востребованном и заслуживающем доверия источнике информации. Согласно полученным данным, российская молодежь, прежде всего, доверяет социальным сетям. Социальные сети респонденты используют в основном для потребления информации о культуре и развлечениях, о своем окружении, о моде и стиле жизни, о социальной проблематике и политике. Современная российская молодежь все активнее проявляет свою заинтересованность в участии в политических процессах. Их особенно интересует ряд актуальных вопросов, в основном касающихся прав человека и личных свобод, миграции, национализма и др., которые не просто встраиваются в дискурс общеевропейских ценностей демократии, но воспринимаются в контексте борьбы за социальную справедливость, что становится вопросом личного выбора и самореализации.

\section{Заключение}

Теория использования и удовлетворения применительно к молодежной аудитории демонстрирует изменения в основном в связи с распространением социальных сетей, которые формируют среду существования современного молодого человека и, соответственно, обладают качествами и характеристиками не только медиа, но и социального пространства. В результате трансформируются потребности аудитории, которая может не только получить от процесса медиапотребления информацию, знания и развлечения, но и удовлетворить запросы, связанные с социальной природой человека - к таким, прежде всего, относятся социализация и самореализация.

Массовая коммуникация традиционно играла важную роль в социализации человека. Уже на раннем этапе теоретического осмысления этого процесса было отмечено, что массовая коммуникация как подсистема общества выполняет функции наблюдения за окружающим миром, корреляции с социальными структурами общества и передачи культурного наследия. Сегодня, в условиях 
смены традиционной массовой коммуникации новой - цифровой диверсифицированной медиакоммуникационной системой (Вартанова, 2001), когда в центре исследовательского внимания оказываются медиа, вопрос медиасоциализации современного человека актуализируется. Превращаясь из социального института, каковым были СМИ, в социальное пространство и принципиально иную среду обитания, медиа обладают несколько иным, чем прежде, потенциалом социализации аудитории, особенно молодежной. Свойства медиа как среды интенсифицируют медиасоциализацию, делая их влиятельным агентом первичной социализации, что напоминает воздействие на социализантов в локальных культурах (Gladkova, Korobeinikova, 2016).

Молодежь нередко стремится находить себе сообщества по интересам как в реальной жизни, так и в виртуальной, чтобы реализовать в контакте с близкими по духу людьми свои базовые потребности.
При создании и распространении медиаконтента, при получении его одобрения членами сообщества молодые люди в медиапространстве не только социализируются, но и самореализуются. Таким образом, успешная медиасоциализация становится залогом осуществления начальных этапов медиасамореализации как процесса актуализации различных сторон личности в медиапространстве, приносящих удовлетворение от жизни (Dunas, Vartanov, 2020)

Многие концепции медиапотребления и медиаповедения аудитории в цифровой среде сегодня формулируются на основе медиапрактик молодых людей - «цифровых аборигенов» (миллениалов и поколения Z), но экстраполируются на аудиторные практики в целом (Vartanova, Gladkova, 2019). Такой подход оправдан: молодежь становится трендсеттером процессов, которые завтра будут определять будущее медиаиндустрии и, соответственно, ее актуальное теоретическое понимание.

Исследование выполнено за счет средств гранта РНФ (проект № 18-78-10090).

Научный коллектив: С.А. Вартанов, Д.М. Вьюгина, А.Н. Гуреева, Д.В. Дунас (руководитель), Д.Ю. Кульчицкая, Э.В. Самородова, Е.А. Салихова, А.В. Толоконникова, Г.С. Филаткина.

\section{Библиография}

Вартанова Е.Л. К вопросу об актуализации теории журналистики и теории СМИ // Вопросы теории и практики журналистики. 2017. Т. 6. № 1. С. 5-13.

Вартанова Е.Л. Новые проблемы и приоритеты цифровой эпохи // Информационное общество. 2001. № 3. С. 50-56.

Вартанова Е.Л. Современные российские исследования СМИ: обновление теоретических подходов // Вестн. Моск. ун-та. Сер. 10: Журналистика. 2015. № 6. С. 5-26.

Солдатова Г.У., Рассказова Е.И., Нестик Т.А. Цифровое поколение России: компетентность и безопасность. М.: Смысл, 2017.

Ткачева Н.В., Вартанов С.А., Дунас Д.В., Гуреева А.Н. К вопросу о теоретическом понимании новостей в цифровую эпоху: трансформация структуры, сил влияния, «жизненного цикла» // Вестн. Моск. ун-та. Сер. 10: Журналистика. 2016. № 3. С. 3-16.

Финк К. Стратегический газетный менеджмент. Самара: Корпорация «Федоров», 2004.

Berger P.L. Luckmann T. (1966). The Social Construction of Reality: A Treatise in the Sociology of Knowledge. New York: Doubleday\&Company. 
Castells M. (2001) The Internet Galaxy: Reflections on the Internet, Business, and Society. Oxford, New York: Oxford University Press.

Couldry N., Hepp A. (2016) The Mediated Construction of Reality. Cambridge: Polity.

Deci E.L., Ryan R.M. (2008) Self-Determination Theory: A Macrotheory of Human Motivation, Development and Health. Canadian Psychology 49: 182-185.

Dunas D.V., Vartanov S.A. Emerging Digital Media Culture in Russia: Modeling the Media Consumption of Generation Z. Journal of Multicultural Discourses, 2020. DOI: 10.1080/17447143.2020.1751648

Gladkova A.A., Korobeinikova K.A. (2016) Examining Public's Exposure to Reports about Ethnic Groups in Mainstream Russian Media. Psychology in Russia: State of the Art 9 (1): 164-177.

Katz E., Blumler J.G., Gurevitch M. (1973) Uses and Gratifications Research. Public Opinion Quarterly 37 (4): 509-523.

Kurzban R., Burton-Chellew M.N., West S.A. (2015) The Evolution of Altruism in Humans. Annual Review of Psychology 66: 575-599. DOI: 10.1146/annurev-psych-010814-015355

Lang P.J., Bradley M.M. (2010) Emotion and the Motivational Brain. Biological Psychology 84 (3): 437-450.

Lee C.S., Ma, L. (2012) News Sharing in Social Media: The Effect of Gratifications and Prior Experience. Computers in Human Behavior 28 (2): 331-339.

Maslow A. (1970) Motivation and Personality. New York: Harper\&Bros.

McQuail D. (2002) Mass Communication Theory. London: Sage.

Palmgreen P., Wenner L.A., Rayburn J. (1980) Relations between Gratifications Dought and Obtained: A Study of Television News. Communication Research 7 (2): 161-192.

Quan-Haase A., Young A. (2010) Uses and Gratifications of Social Media: A Comparison of Facebook and Instant Messaging. Bulletin of Science, Technology \& Society 30: 350-361. DOI:10.1177/0270467610380009

Sundar S.S., Limperos A.M. (2013) Uses and Grats 2.0: New Gratifications for New Media. Journal of Broadcasting \& Electronic Media 57 (4): 504-525.

Vartanova E.L., Gladkova A.A. (2019) New Forms of the Digital Ddivide. In: Digital Media Inequalities: Policies against Divides, Distrust and Discrimination. Goteborg: Nordicom bokserie, pp. 193-213.

White D.S., Cornu A.L. (2011) Visitors and Residents: A New Typology for Online Engagement. First Monday 16 (9). DOI: 10.5210/fm.v16i9.3171 